\title{
ARTE CONTEMPORÂNEA E A (RE) CONSTRUÇÃO DA MEMÓRIA
}

\author{
Aline Hubner Freitas' \\ Magali Melleu Sehn²
}

DOI: https://doi.org//0265 I2/museologia.v7il 4.18393

\begin{abstract}
RESUMO
Ortigo tem como objetivo apresentar uma reflexão da arte contemporânea e a preservação da memória. Aborda sobre os principais pontos da arte contemporânea a partir da década de 60, a qual designa as formas artísticas surgidas no início desta década, que recorrem a todo tipo de materiais e processos, liberdade que permanece até hoje. Essas obras colocam em contraposição o sistema de registro e documentação, modelos de circulação e interação, diante de uma produção que está cada vez menos preocupada com sua continuidade memorial. Através dessas considerações de materialidade, performances, vídeos, arte digital, efemeridade e arte conceitual, os questionamentos apresentados são: qual o lugar de memória na arte contemporânea? qual o papel do museu nesse novo contexto? quais são os desafios de lidar com a preservação da obra e a intenção do artista? Sendo assim, busco responder esses questionamentos, estabelecendo relações entre os conceitos de memória, museu, arte contemporânea e preservação. Exemplificando através de um estudo sobre a obra "Retratos, 2013" do artista Oscar Munõz, que fundamenta sua pesquisa artística através dos conceitos de memória, efemeridade e instante temporal.
\end{abstract}

\section{PALAVRAS-CHAVE}

Arte contemporânea, memória, museu, registro, patrimonio cultural.

\begin{abstract}
This article aims to present a reflection of contemporary art and memory preservation. Approaches on the main points of contemporary art from the 60's, which designates the artistic forms which occurred earlier this decade, using all kinds of materials and processes, freedom that remains today. These works pose against the system of registration and documentation, models of movement and interaction, in front of a production that is increasingly less worried about its memorial continuity. Through these considerations of materiality, performances, videos, digital art, ephemerality and conceptual art, the questions are: what is the place of memory in contemporary art? What is the role of the museum in this new context? What are the challenges of dealing with the preservation of the work and the artist's intention? Therefore, I seek to answer these questions, establishing relationships between the concepts of memory, museum, contemporary art and preservation. Exemplifying through a study on the work "Retratos, 2013" by the artist Oscar Muñoz, who bases his artistic research through the concepts of memory, ephemerality and cultural heritage.
\end{abstract}

\section{KEYWORDS}

contemporary art, memory, museum, registry, cultural heritage.

\footnotetext{
' Formada em Artes Visuais Bacharelado na UFSM/UFMG, tem como habilitação Pintura. É mestranda da linha de pesquisa Teoria e História das Artes Visuais, na UDESC, participa do grupo de pesquisa História da

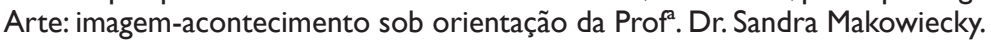

${ }^{2}$ Professora adjunta do Departamento de Artes Plásticas da Universidade Federal de Minas Gerais/UFMG
} 


\section{Narrando uma história}

No contexto da história da arte, é possível perceber as manifestações de diferentes movimentos artísticos nacionais e internacionais ao longo dos séculos. Para analisar esses movimentos artísticos, é fundamental entender a arte e suas relações inseparáveis com a política, sociedade, religião, economia, cultura, enfim, questões que estão inseridas na criação desses movimentos e que refletem no contexto das obras de arte. A partir da análise de transformações de conceitos artísticos, é possível realizar um breve resumo das artes plásticas, desde a década de 60, abordando a arte contemporânea e sua inserção na sociedade.

$\mathrm{Na}$ década de 60, Michael Archer (2012), relata que:

Ainda era possível pensar nas obras de arte pertencendo a duas grandes categorias: a pintura e a escultura. Porém, já haviam começado a desafiar esse "duopólio" através da inserção, das colagens cubistas, performance futuristas, eventos dadaístas e fotografia. Os temas das obras de arte retratavam o cotidiano, os objetos nomeados como arte, pelos próprios artistas, eram fabricados em série, transformados em arte. (Archer, 2012:03)

Neste período Duchamp, criou o termo "ready - made" para descrever os objetos fabricados em série que ele escolhia, comprava e designava como obra de arte. $O$ objetivo era fazer com que o observador pensasse sobre 0 que definia a singularidade da obra de arte em meio a multiplicidade de todos os outros objetos. Perante esses conceitos, um outro termo usado nesse contexto é assemblage, conforme a definição dos autores Archer (1997) e Argan (1992). Estes relatam que o princípio da realização da assemblage é a "estética da acumulação", visando romper as fronteiras entre a arte e vida cotidiana. A principal ideia que sustenta as assemblages diz respeito à concepção de que os objetos díspares reunidos na obra, ainda que produzam um novo conjunto, não perdem $\circ$ sentido original. Partindo de um interesse pelo corriqueiro, 0 acaso e um novo senso visual, vimos caminhos que levaram a arte à duas direções: a Pop Art e o Minimalismo.

A Pop Art foi reconhecida primeiramente nos Estados Unidos, com temas urbanos e banais, em que os artistas defendem uma arte popular que se comunique diretamente com o público. Nesse sentido, a Pop Art se coloca na cena artística em fins da década de 1950 como um dos movimentos que recusam a separação arte/vida. Após a Pop Art, a arte cinética obteve grande repercussão estava relacionada à ideia de movimento. Através do conceito de arte cinética, Argan (1992) aborda que o cinetismo rompe com a condição estática da pintura, apresentando a obra como um objeto móvel. Uma das derivações da Arte cinética de grande repercussão foi a Op Art ou Optical Art, que explorava a potencia da arte e a cor, para criar ilusão de movimento.

Outros movimentos na história da arte surgiram modificando os conceitos artísticos e suas produções, como o Minimalismo, que retratou a continuação da pintura por outros meios, renunciou a unicidade dos objetos de arte e sua diferenciação dos objetos comuns. Em meados dos anos 70 houve uma crescente facilidade de acesso e uso das tecnologias de comunicação, como a fotografia, filmes e sons. A consequência desse período foi a dificuldade de compreender no que a arte estava se transformando. $O$ pós-minimalismo surge com o conceito de que o estilo próprio do artista deixa de fazer sentido. Reagia contra a rigidez formal, o que importava era o processo da obra, os materiais e estágios de manipulação para executá-la. A arte conceitual dá prosseguimento ao que já havia sido iniciado nos anos 20 com o dadaísmo, o serialismo está 
presente, assim como o entendimento de que a obra de arte final não deveria ilustrar ou estar subordinada a nenhuma outra coisa, sendo que a ideia ou o conceito da obra é o seu aspecto mais importante. Em 1969, a arte Povera, expressão criada pelo crítico italiano Germano Celant, prestava atenção nos fatos e ações, com o tratamento efetivo dos materiais. Arte Povera, que em italiano significa "arte pobre", foi um movimento artístico pertencente a contracultura e ganhou esse nome, pois os artistas criavam obras de arte utilizando materiais simples e sucatas. Após esse novo conceito de que cada material representado significava a ele próprio, a obra de arte não estava preocupada com a definição subjetiva, não era algo visual ou estético, mas um espaço a ser adentrado e experimentado de um modo físico pleno. Deriva desta compreensão, a Land Art, que irá desenvolver a relação entre um local particular no meio ambiente e os espaços anônimos.

Outra conquista deste período diz respeito ao suporte, que nessa década agregou o uso do corpo e a participação do público nas obras de arte. Surgiram de forma programática, as performances, arte pública, instalações, vídeos, arte digital. Observamos o crescimento de manifestações artísticas que implicavam em uma arte difícil de consumir, preservar e documentar, uma arte que negava as vendas do objeto, carregava uma certa força política e ideológica contrária aos dogmas da economia capitalista de mercado. A desmaterialização da obra e a impessoalidade da execução caracterizaram os anos 70, mas de certa forma, a predominância das ideias de Duchamp foram ultrapassadas nos anos 80 , pelo restabelecimento da habilidade manual, por meio do prazer de execução que traz de volta a tradição da pintura. Algumas questões se sobressaem como a morte do progresso em arte, a ruptura com uma ideia de história da arte linear, mas uma multiplicidade de abordagens, liberdade artística extremada, empregando o artesanato, outras técnicas, materiais e temas. Nesse período, muitos museus de arte contemporânea são criados, o estoque restrito desse novo processo da arte, resultou no aumento do valor das obras, renovando o interesse pela pintura, que consequentemente expandiu o mercado.

Archer (20I2) relata que o mercado descobriu uma forma de colocar a arte publica em cena.A popularidade da instalação, a maturidade da vídeo obra, as estratégias transformadoras da arte pública e a contínua relevância da obra dirigida aos problemas sociais, podem ser testemunhas das várias exposições produzidas nesse período. No início dos anos 90 , os artistas pintavam objetos prontos, comprados como produto já manufaturados.

Os temas tratavam de críticas sociais, políticas e os materiais utilizados são perecíveis, efêmeros e precários. $A$ arte tem mais um propósito: observar a arte não significa consumi-la, mas tornar-se parte de um mercado ao qual pertence essa arte e o espectador. Nesse período ela significa um encontro contínuo e reflexivo com o mundo em que obra age como iniciador e ponto central da investigação do significado, todavia, observa-se que ao longo de todo o período da arte contemporânea as preocupações com a beleza e com as qualidades modificadoras da forma nunca foram rejeitadas por completo.

Ao explicitar brevemente e em forma linear, buscando sobretudo contextualizar as transformações e novas proposições surgidas com maior predominância a partir dos anos 60, percebe-se que a partir desta década, os materiais utilizados nas obras e o uso de vídeos, performances, instalações, acabaram por colocar novos problemas e a forjar por assim dizer, novas formas de conceber o processo de documentação, preservação, aquisição da obra e principalmente a conservação das obras. Este trajeto serviu apenas para apontar tais proposições 
artísticas, que queremos descrever na sequência.

\title{
Arte e a reconstrução da memória
}

Oliveira (2013) apresenta em seu artigo, a compreensão da obra de arte enquanto matéria nos anos de 1960. Ele relata que:

\begin{abstract}
Nessa época, tornou-se evidente que a conservação de processos artísticos e seus suportes materiais eram incompatíveis com muitas das poéticas concebidas desde então. Buscava-se, em certo sentido, desfazer-se de algumas convenções que envolviam acordos institucionais. No Brasil, os artistas começaram a problematizar a homogeneidade do suporte, entendido por meio de sua essência material, no mesmo período [...] Todavia, o predicado do registro veio como elemento necessário para a construção narrativa que desse sentido memorial aos happenings, às performances $e$ às intervenções da época. (Oliveira, 2013:02)
\end{abstract}

Os registros que facilitavam a documentação foram realizados através de fotografias, vídeos, películas, além da escrita documental. Entretanto, penso ser fundamental registrar em papel, informações sobre obras executadas uma ou mais vezes pelos seus produtores, como eram realizados anteriormente. $O$ uso do papel nas escritas e projetos documentais possui relevância por ser um material de conservação tradicional, é uma forma segura de registrar a memória das obras de arte, com o benefício de um maior tempo de duração, sendo armazenado em condições adequadas, a despeito de toda a tecnologia hoje existente.

Segundo Oliveira (2013), desde os anos de 1990, tomou forma o debate sobre como alguns destes registros estavam ultrapassando seu estatuto documental para se tornarem elementos constitutivos do próprio ato poético da obra. Sendo assim, permanecem com a função não somente de ser o registro da obra, por vezes é a própria obra. Muitas vezes essa documentação é vendida para os museus que querem adquiri-la. Esse registro pode ser em forma de projeto, desenhos, croquis ou a partir de fotografias e vídeos. $O$ autor ressalta que em muitos casos, tal transformação contraria a intencionalidade primeira do registro e o julgamento dos próprios artistas, como Barrio e Marina Abramovic, que recusam considerar tais documentos como próprios do processo artístico. Segundo o autor, o sentido histórico da arte em processo e sua circulação e reapresentação ao público têm transformado muitos desses registros em elementos de apreciação estética, até porque gerações posteriores de artistas vêm utilizando o registro não mais como documento representacional, mas como componente indissociável da trama poética e especulativa que compõe as obras, como bem exemplifica a produção de Anna Bella Geiger e Letícia Parente, já nos anos de 1970. O autor afirma que:

A própria imagem da arte tornou-se arte, justamente porque tal imagem, dentro dos circuitos autorizados, comporta-se, em sua estética, de maneira quase autônoma. A imagem da arte é a arte que vende a si mesma. Esta é uma afirmação polêmica, que mobiliza diferentes campos de conhecimento, afinal pergunta-se qual o limite entre o registro de uma performance e a própria performance enquanto ato finito inscrito num dado espaço-tempo. (Oliveira, 20 I3:

Analisando-se essa citação, pode-se perceber, concordando com o autor, que muitos artistas ligados às redes de circulação da arte dissolveram os limites entre os registros documentais e os registros poéticos, o que ampliou nossa per- 
cepção sobre os impactos da arte e seus públicos.A documentação da arte contemporânea através da utilização do registro fotográfico, fílmico ou videográfico de processos relacionais, de performances e de intervenções artísticas em espaços públicos ou institucionais como componentes poéticos mais recentemente, mostra-nos que os artistas passaram a se posicionar diante do universo imagético. Segundo o autor, esses registros são manipulados como elemento positivado no processo de recuperação e atualização dos trabalhos "imateriais". Funcionam como desdobramentos narrativos sensivelmente atrelados aos atos fundadores, que passam a depender deles numa complexa dimensão de virtualidade.

\section{A importância da memória e registro na arte contemporânea}

Pensar sobre a memória na arte contemporânea, seus registros, preservação e documentação, fazem surgir varias questões, mas nominaremos sobretudo, duas questões: a importância desses registros para o artista e para os historiadores da arte. Seguindo o raciocínio de Oliveira (20l3), este afirma que para o artista, a memória de seu percurso, quando o mesmo tem essa intenção, esta deve ser de registrar sua carreira, seu percurso artístico, mas não é tão problemático, se comparado com as instituições e historiadores. As instituições precisam de registros das obras, seja para servirem de testemunhas, seja para dar legitimidade, seja para realizar a continuidade das narrativas da história da arte, realizando comparações críticas do acervo contemporâneo. Já os historiadores precisam seguir a tradição metodológica que institui a disciplina, visando uma continuidade da história da arte obtida através da cronologia, para depois realizar relações anacrônicas de movimentos, contextos, imagens e significados. Refletindo conforme o autor sugere, pensamos: como podemos fazer uma história da arte sem a obra ou registro?

Continuando esse raciocínio, Oliveira nos apresenta outros questionamentos:

Se, para esta minoria de artistas, não há sentido em produzir uma memória da arte, como discutir a obra de determinado artista que pode apenas avisar, por meio de redes sociais, que realizará uma performance pelas ruas de uma grande cidade, mas que além de não registrá-la se recusa a comentá-la? Será que essa obra existiu? E, se a obra não existe enquanto discurso, como produzir uma narrativa histórica? Como instituir uma legibilidade e uma legitimidade para ela? Sem a obra e sua legitimidade há artistas? Se não há arte nem artistas, o problema parece resolvido, pois para que serviriam os historiadores da arte? (Oliveira, 2013:04)

Partindo desse contexto, é importante pensar como os artistas contemporâneos estão refletindo ou não, sobre a preservação de suas obras, antes mesmo de suas criações, quais as consequências que a falta de registros poderá ter no futuro, tanto para a memória da obra e dele próprio, na história da arte. Relacionando com as instituições, o museu deve se adaptar a uma série de fatores, em especial, no fator de conservação, visto que é preciso pensar a melhor forma de guardar as obras contemporâneas, pois para estas não há estudos suficientes e satisfatórios que deem conta de abordar formas ideais de conservação, através dos diversos materiais que são utilizados.

É necessário respeitar a questão da proposta de conservação da obra de arte contemporânea, através do conceito que o artista abordou na sua criação, pois a conservação pode ser pensada ou não pelo artista e este é um fator a ser considerado. Esse processo depende do conceito que envolve a obra,como por exemplo, uma proposta que tenha como poética central sua efemerida- 
de. A instituição que pretender adquiri-la, deve ter consciência do contexto e conceito em que ela foi realizada. Em obras de caráter efêmero, é importante a preservação dos seus registros. Há também, o problema de conservação de objetos de grandes dimensões, que nem sempre cabem no espaço da reserva técnica. Outra dificuldade diz respeito à obras que são realizadas em espaços públicos, as quais foram criadas para um determinado lugar. Muitas delas só tem sentido naquele espaço e contexto, estão interligadas com o conceito de site specific (trabalhos realizados em locais de exposição específicos e que possuem relação com o lugar e a cidade) que por sua vez, está relacionado com a arte pública e land art.

\section{Museu como local de memória na arte contemporânea: terceira questão}

O trabalho do museu não está relacionado somente à integridade física da obra, a instituição também conserva memórias, neste caso da produção artística contemporânea. Candau (20I2) chama os museus de "casas de memória" e diz que o seu desenvolvimento está relacionado à vontade de conservar, de guardar as experiências humanas na memória. Pierre Nora (1984) denominou locais de memória, aqueles onde a memória se cristaliza, que surgem quando não existem mais meios de memória. Neste contexto, a arte contemporânea ainda possui meios de memória, pois permanece em produção constante, por isso requer os cuidados com a preservação da arte, entendendo a ideia do conceito que o artista pretende impregnar em sua obra, porém sempre registrando o que for possível, para guardar essa memória no tempo que está por vir, continuando as reflexões da eterna história da arte.

Taddei (2012), afirma que apesar de ser uma memória viva, a arte contemporânea já necessita de lugares de memória. No entanto, um ponto importante para reflexão da produção na arte contemporânea, é que mesmo não tendo uma ampla aceitação social, o que por vezes, depende dos conceitos que o artista cria para sua obra e provavelmente, pela sua imensa diversidade e complexidade, o local de memória é relevante para o registro da arte realizada hoje, armazenando informações externas à obra sobre o contexto histórico, social e político atual.Apesar de estar relacionada à identidade e à memória de um grupo específico, a arte contemporânea, não é uma produção recente e faz parte da história da arte, chamando atenção para a questão:

$$
\begin{aligned}
& \text { a produção artística contemporânea, por ser tão plural na escolha } \\
& \text { dos materiais, nas configurações e nas poéticas, é complexa de se } \\
& \text { compreender e também de se conservar. A dificuldade de compre- } \\
& \text { ensão por parte do público dificulta a formação de uma memória } \\
& \text { acerca desta produção. (Taddei, 2008: I2) }
\end{aligned}
$$

Emerge destas problemáticas, o pensamento de que precisamos de um processo de educação cultural que deveria vir com incentivo governamental e de politicas publicas, visando o aprendizado das artes em geral, tanto nas escolas como nas instituições culturais, formando uma base para que a criança em tenra idade, possa despertar a sensibilidade e aprender a usar a arte no seu desenvolvimento intelectual, transformando seu olhar e ampliando visão sobre o mundo, auxiliando no seu aprendizado pessoal.

Segundo Candau (2012), não basta que se transmita uma história e memória, é preciso haver receptores, para que ela não se perca. Os receptores, ou seja, o público, precisa ter acesso ao conhecimento e à arte, nesse caso, acesso 
à obras de arte e deve ter também, condições e tempo de decifrar, entender e refletir sobre este legado cultural. Para ter este conhecimento, é preciso que o objeto artístico dure tempo suficiente para ser compreendido. A compreensão deve ser facilitada com a bagagem cultural de cada ser. Sendo assim, os meios para que a preservação da arte aconteça, mesmo que em algumas obras, o conceito de efemeridade seja a tônica, mesmo que não seja proposta do artista, a concepção de uma obra de duração mais longa ou mesmo que ele não se importe com nada disso, nem deseje, devemos refletir sobre qual a melhor forma (dentro das nossas possibilidades), de efetivar o registro dessa criação, visando proporcionar preservação da memória e continuidade da história da arte em suas relações de contexto social, histórico, cultural.

\title{
Os papéis da preservação, educação e instituições
}

Para isso contamos com as instituições, museus, escolas, galerias, governos, que podem incentivar, a consciência e respeito da arte através da educação, preservando o patrimônio cultural, independente de qual tempo ele pertence. Especificamente, na arte contemporânea, as equipes dos museus estão se adaptando através da interdisciplinaridade, para encontrar soluções e dividir responsabilidades de preservação. Conforme a autora Sehn (20I0), coloca:

\begin{abstract}
o estabelecimento de novas formas de operar e de novas relações entre os profissionais, assim como o papel do artista no processo de preservação da arte contemporânea, constituem o foco do debate atual. Compartilhar riscos e dividir responsabilidades constitui o ponto de partida para o encontro de soluções compatíveis com as novas propostas artísticas. (Sehn, 2010:62)
\end{abstract}

Uma modificação no processo de preservação é a equipe de profissionais interdisciplinares, os quais estudam diferentes áreas ou afins, todos em busca de um mesmo objetivo, preservar a memória, nosso patrimônio, expandindo a cultura na sociedade. As instituições em geral e apoio cultural dos órgãos responsáveis, contribuem com a preservação da arte, independente do contexto temporal que se encontra. Para isso ser realizado, na arte contemporânea, são fundamentais a conservação, documentação e preservação da memória com o auxílio do museu. É através dele que estes processos podem se dar de forma mais abrangente e mais acessível ao público.

Sendo assim, o autor Gomes (2003), relata os cuidados que devemos ter ao pensar o museu na arte contemporânea:

quando tratamos de arte contemporânea no museu, estamos pen-
sando em uma arte que efetivamente existe e requer uma atenção
inevitável, independente de nossa compreensão de sua razão pri-
meira de ser e ainda de nossa capacidade técnica e instrumental
para preservá-la. Estamos pensando na obrigação do agora dos
museus, imprensados entre as tradições antiga e moderna, preocu-
pados com a preservação para um futuro. Como trabalhar o agora,
não esperando a consagração desta produção, trabalhar com o pre-
sente vendo o passado (como base, modelo e/ou parâmetro) e não
ambicionar projetar o futuro? Estabelecer, enfim, uma visibilidade
para o momento atual permitindo que esta produção seja efetiva-
mente recebida pelo público? (Gomes, 2003:I)

Estamos entendendo o sentido da preservação para o futuro, através da documentação tanto como registro, esquema de montagem, que irá auxiliar na 
reexibição da obra, assim como, preservando a memória da arte contemporânea ao mesmo tempo, que essa arte acontece. Com isso, é possível perceber, a importância de continuar a história da arte, suas reflexões, críticas sociais, políticas e o contexto de mundo que a arte participa, considerando que, sempre existiu essa reflexão ao longo dos séculos, independente do seu contexto temporal.

No entanto, devemos expandir nossos conceitos tradicionais e buscar cada vez mais uma nova forma de abordar a arte contemporânea na educação, sociedade, museus, instituições em geral. Integrando uma equipe de profissionais de diversas áreas, trabalhando em conjunto, buscando a melhor adaptação e reformulação de novos conceitos na arte contemporânea. Inicialmente, pela base educacional, na educação infantil, ampliando para disciplinas de conservação, preservação e patrimônio, obrigatórias dentro das universidades, independente do curso ser técnico ou superior, considerando a cultura como direito de qualquer cidadão, fundamental para a formação crítica e intelectual.

Sendo possível, formar diálogos, conexões, com as obras anteriores realizadas ao longo da história da arte, entendendo que é importante relacionar as obras, instigando conviver com todos os contextos anteriores, independente dela ser tradicional, moderna ou contemporânea. Buscando enriquecer nosso conhecimento, desenvolvendo a capacidade crítica, a reflexão, atendendo assim, todos os públicos e valorizando os períodos da história e obras de arte com suas singularidades.

Para o autor Menezes (20I0), a educação dos museus é muito importante, ele defendeu em uma conferência, a proposta de que:

Trabalhar educação no museu não é levar para lá toneladas de estudantes que copiam as legendas, afirmou Menezes. Museu não é o lugar da palavra escrita, ela já tem seus suportes. $O$ museu tem que transformar a percepção, e os educadores devem explorar o que define a personalidade do museu. (Menezes, 20l0:I)

Reforçando assim, a importância da formação educacional, constituindo uma base desde a educação infantil para ter uma consciência de respeito, preservação e direitos em relação a cultura. Menezes (20l0) afirma, sobre o papel do museu contemporâneo na formação da memória, que será de proporcionar uma visão crítica, através do confronto dos conceitos artísticos, visando um maior entendimento dessas memórias.Através da sua citação, podemos perceber esse diálogo:

Prefiro considerar que o museu - principalmente histórico, em vez de espaço de produção, preservação e reforço de uma memória - transforme-se num espaço de confronto, visão crítica e entendimento das memórias. Naturalmente, não estou ignorando aqui as práticas sociais relativas à memória que segmentos da sociedade fazem do museu nem seu direito a construir suas próprias memórias. [...] Estou apenas privilegiando a necessidade inelutável de espaços de contraponto, para que a sociedade não seja apenas um punhado de identidades blindadas e autocentradas, apenas justapostas. (Menezes, 20I I:I)

Além, dessas considerações, outra questão que o autor expõe sua opinião, é a respeito, da criação dos museus virtuais. Questionando quais são suas vantagens e consequências, o desafio do uso da tecnologia com a arte contemporânea nas instituições museológicas, sendo assim relata: 
Sou totalmente a favor do uso da informática nos museus. Sou da mesma maneira totalmente contra a redução do museu a um único modelo ideal, como camisa de força, o museu virtual. Quando se fala de museu virtual, a referência é, sobretudo, à exposição no espaço físico: a organização interna, assim como a circulação na web são questões de outra natureza. A referência é também à desmaterialização da percepção. Depois, os modelos virtuais - inclusive os de maior sucesso de público - funcionam muito aquém do extraordinário potencial que a informática poderia trazer para o tal museu tradicional. Isso revela que o museu é que está servindo à tecnologia - numa de suas vertentes mais tradicionais, a dos jogos interativos e dos recursos de imersão - e não se servindo da tecnologia para atender ao enorme leque de funções cognitivo-documentais, culturais e educacionais que ele pode desenvolver. (Menezes, 20 I I:I)

Através dessa percepção, há um limite entre a tecnologia e a sensibilidade da compreensão do mundo, com as reflexões da matéria, criação, conceitos, sensações, significados, que a arte expressa por si só. O autor MENEZES (20I I), em uma entrevista realizada pelo SESC, de São Paulo, afirma que:

A reflexão não se dá bem com o instantâneo. Como na estética do videoclipe, valoriza-se exclusivamente a imersão. E a imersão redutora, sem posterior emersão, pode conduzir ao afogamento. No campo do conhecimento e da formação crítica, que exigem distância e tempo, é o que tem acontecido.A percepção se dilui na sensação, o que é sem dúvida prazeroso e positivo, mas compromete a consciência da mediação sensorial da vida - raiz de inteligibilidade. Além do mais, quando a bateria de sensações é excludente de alternativas, até a interatividade pode ser enganosa e corre o risco de mascarar passividade intelectual sob a aparência de hiperatividade gestual. (Menezes, 20I I:I)

Essa reflexão, da crítica perante a obra não se dá pelo instantâneo, através de um acesso virtual, mas sim pela vivência e uso dos sentidos no contato obra e espectador. Portanto, nada substitui o contato pessoal com a arte, a importância de restabelecer a memória nas instituições, explicando as reflexões que a arte proporciona.

\section{Registro, memória, efemeridade e obras de arte}

Para finalizar esses questionamentos, de registros e a arte contemporânea, cito um artista que trabalha em suas obras com as questões de efemeridade, memória e esquecimento.

O artista Oscar Muñoz nasceu em Popayán, Colômbia e se formou em I97I a partir da Escuela de Bellas Artes de Cal, onde continua a viver e trabalhar. Realiza sua produção nas áreas da fotografia, gravura, desenho, instalação, vídeo e escultura, interligando as fronteiras entre essas práticas. Oscar Muñoz, refletiu sobre a capacidade que as imagens possuem, em reter a memória. A relação da memória em suas obras, tem como base, a fotografia, mas essa relação pode ser chamada de complementar, uma vez que seu trabalho se refere a aspectos da fotografia, quase nunca usados como o resultado final do processo da obra de arte.

Muñoz começou sua carreira na década de 70 em Cali, no meio de um movimento cultural intenso e multidisciplinar que incluía escritores, cineastas, fotógrafos e artistas. Muitos deles, como Andres Caicedo, Carlos Mayolo, Franco e Luis Ospina Fernell são considerados pioneiros em suas áreas.

Nesta fase, Muñoz realizou desenhos de grande formato, que se tornaram 
visíveis no ambiente de cortiços tristes e sórdidos na carga de trabalho psicológico profundo. Sua obra teve desde então vários recursos que tenham permanecido constante em sua obra posterior: o interesse pela experiência social, técnico em lidar com o material, o uso da fotografia como uma ferramenta de memória, com a reflexão constante sobre os seus limites e o inquérito sobre as possibilidades dramáticas de luz e sombra em relação à definição da imagem.

Em meados dos anos 80, Oscar Muñoz longe de técnicas tradicionais como desenho em papel ou gravura em metal e começa uma experiência com novos processos e mídias incomuns. Nos anos 90 , década de noventa, quando no trabalho uma reformulação radical do exercício de desenho e gravura, os usos da fotografia, a relação da obra com o espaço em que ele está instalado e é apresentado o papel do espectador e da passagem do tempo na formação da imagem.

A decisão do artista a abandonar os formatos e técnicas tradicionais, mantendo suas principais fontes e mecanismos para investigar o efêmero, resultou em tanto um trabalho baseado nas qualidades intrínsecas dos materiais utilizados e associações poéticas que eles encarnam. $O$ uso de elementos-chave, tais como água, ar e fogo em várias de suas obras refere-se aos processos, ciclos e manifestações transcendentais da vida, existência e morte.

Por mais de vinte anos, Muñoz tem produzido trabalhos que investigam a natureza da representação por meio de técnicas de impressão fotográfica e mecânicas pouco ortodoxas, bem como através de obras que empregam vídeo. Muitas vezes, essas imagens são criadas usando materiais inusitados e instáveis como a respiração humana, água, luz, cera e pó como forma de chamar a atenção para a precariedade da vida humana, o narcisismo e altruísmo. Suas obras são documentadas por vídeos, fotografias e registros digitais. Novamente voltamos na importância de preservar essa memória através da documentação adequada, continuando a história da arte e incluindo esse artista dentro desse contexto.

Um exemplo é uma de suas obras, realizada em 2003, com o título "Retratos, 20 I3", onde o artista desenha com água e o auxílio de um pincel uma série de retratos de rostos humanos, em um suporte de concreto. $O$ material efêmero utilizado, neste caso a água, vai evaporando ao longo da criação do desenho. Com isso, sua obra (os retratos), desaparecem, então o artista cria um novo retrato a partir dos vestígios do antigo, assim, sucessivamente. Através desse exemplo de obra contemporânea, podemos refletir alguns questionamentos, os quais são: como vamos preservar a memória da arte que acontece hoje? o que vai ficar para o futuro?, quais obras serão selecionadas para o futuro? Como preservar esse tipo de memória? Entretanto, os únicos registros de sua obra, que possui a proposta de efemeridade, são realizados através da documentação em vídeos e fotografias. Sendo assim, retomamos esses questionamentos realizados ressaltando, a importância da preservação da memória independente do conceito que o artista propõe, deixando registrado a arte de hoje para a sociedade na constante construção e reconstrução da história da arte.

\section{Considerações finais}

Retornando ao inicio deste texto, em que discorremos e percorremos algumas destas modificações na arte, ressalta à nossa compreensão, a importância de considerar a educação como fator fundamental que deve ser aliada das noções e práticas de preservação de patrimônio de diversas naturezas, educação como aliada do incentivo à cultura. Ha que se reforçar também, a necessidade de adaptações e esforços que devem ser feitos por estudos em museologia, 
para equipar museus que ainda utilizam formas mais tradicionais de salvaguarda de patrimônio cultural. Com o fim do modernismo na arte e o surgimento da pós-modernidade (décadas de 60/70), operaram-se mudanças definitivas relativas à concepção de arte, aos conceitos, às técnicas, aos materiais, portanto, redimensionando os processos poéticos, estéticos, teóricos, o papel do artista e o próprio espaço da arte.A arte produzida na cena contemporânea é, portanto, reflexo dos acúmulos e das experimentações históricas como, também, reflexo do próprio contexto contemporâneo, globalizado, híbrido, acelerado, transdisciplinar, plural, polissêmico, neobarroco, mestiço, aberto à alteridade e tantos outros adjetivos. Justamente por isso, a arte contemporânea combina materiais, linguagens, tecnologias e locais de maneira ilimitada. No caminho da dissolução das fronteiras das linguagens, assimilou os conceitos que se abriram a partir da Arte Conceitual, da Arte Povera, da Arte Processual, da Arte Ambiental, da Performance, da Land Art, entre outras, onde artistas experienciaram o fazer artístico num contexto mais amplo, repleto de possibilidades distanciadas de seu núcleo técnico e formal. Mas como realizar a preservação de tantos estes hibridismos, diferentes materiais, linguagens, tecnologias e locais de maneira ilimitada?

Ao discorrer sobre as obras que colocam em contraposição o sistema de registro e documentação, modelos de circulação e interação, diante de uma produção que está cada vez menos preocupada com sua continuidade memorial, entendemos que pouco se fez e que longo será o caminho a percorrer para realizar essa tarefa. O lugar de memória na arte contemporânea é tema complexo e os desafios de lidar com a preservação da obra e a intenção do artista, expostos por autores que se debruçam sobre o tema, nos mostram que todas as expressões artísticas são a afirmação da liberdade e da criatividade humana e, embora tenham suas próprias especificidades, almejam a mesma coisa: o conhecimento ou a "experiência desmesurada do obscuro", a vida exemplificada pelo desvio, singularidade da arte. Por fim, dentro dessas singularidades e desvios, são obscuras também no momento, as soluções possíveis para tais conflitos, se assim os entendermos.

\section{REFERÊNCIAS}

ARCHER, Arte Contemporânea: uma história concisa. São Paulo, Editora WMF Martins Fontes, 2012.

ARCHER, Michael. Art Since 1960. Londres:Thames and Hudson, 1997.

ARGAN, Giulio Carlo. Arte moderna: do iluminismo aos movimentos contemporâneos. Tradução Denise Bottmann, Frederico Carotti. São Paulo: Companhia das Letras, 1992.

BEIGUELMAN, Giselle. Futuros possíveis: arte, museus e arquivos digitais, artigo Reinventar a memória é preciso, São Paulo, Edusp, 2014.

CANDAU, Joel. Antropologia de La memória. Buenos Aires: Nueva Vision, 2002.

GOMES, Paulo, Jornal do MARGS, $\mathrm{n}^{\circ}$ 87, abril de 2003. 
MENEZES, Ulpiano. Conferência na Escola de Informação UFMG, 24 de setembro de 2010.

MENEZES, Ulpiano. Entrevista realizada pelo SESC de São Paulo, postado em 21 Janeiro de $201 \mathrm{I}$.

NORA, Pierre. Les lieux de Mémoire. Paris: Gallimard, 1984.

OLIVEIRA, Emerson Dionísio Gomes. Registros e ausências: arte contemporânea como desafio para historiadores da arte, Revista Museologia \& Interdisciplinaridade. PPGCinf/UnB, 2013.

SEHN, Magali. Entre Resíduos e Dominós, preservação de instalações de arte no Brasil. São Paulo. Editora C/Arte, 2010.

TADDEI, Fernanda. “ Museu de Arte Contemporânea um lugar para a memória”. XI Encontro Estadual de História, FURG, Rio Grande, 2012. 